\section{Social media - i, me and e}

\author{
Stephen Hancocks OBE \\ Editor-in-Chief
}

Send your comments to the

Editor-in-chief,

British Dental Journal,

64 Wimpole Street,

London,

W1G 8YS

Email bdj@bda.org
Presenters on courses aimed at developing or improving teams sometime use the saying that there is no ' $i$ ' in team. The inference is that there is no room for the individual, or more particularly the individual ego, within a team structure; everyone should be thinking and acting with the group objectives in mind.

Taking the analogy one step further it is pertinent to note that there is an ' $\mathrm{i}$ ' in social and a 'me' in media as the very present phenomenon of social media is having such an impact on all of our lives. How far does the personal impinge on our attitude towards this new entrant into our social and professional interactions? We are all very familiar with the clichés and platitudes surrounding the growth of electronic media but the fact remains that it has provided all of us with the potential to contact anyone else on the planet at any time for whatever motive we wish. A truly startling revolution and one not made by politicians or indeed by political will but made possible by science and technology. As with all research and development it is not the result itself that is important, it is the interpretation and application that determines whether it is implemented for better or worse. The way in which we apply and use electronic media in our daily lives determines whether we view it as a positive force or a curse; or a muddled mixture of both.

\section{BE CAREFUL WHAT YOU POST}

For many dental practices the initial foray has been the creation of a website. As with lots of sites these began as extensions of established literature, leaflets made electronic as it were with information about location, team members, opening hours and so forth. Increasingly, more interactive elements are being incorporated; the ability for patients to make appointments, reminders to patients about upcoming appointments by email and by text to mobile devices, the ability for patients to feedback. From a marketing viewpoint the opportunities are boundless but there are also dangers. The possibility of sites akin to the travel sites of the 'Trip Advisor' type mean that members of the public, or more specifically patients - our patients - have the ability to post comments about our services and skills. If they are good, they are great publicity but if they are equivocal or bad they can be upsetting and damning. Even the General Dental Council (GDC) has noted that there is a possibility of screening such comments in future for the purposes of their awareness of risks in practices and therefore potential fitness to practise issues. ${ }^{1}$
Similar care needs to be taken in regard to social sites on which images, comments and blogs might reflect poorly on a professional reputation; the 'I' and 'me' being of particular significance. As I overheard one parent saying recently of their son's Facebook page, 'you'd better clean that up before you start applying for interviews'. Again, with pluses and minuses, as Facebook could be instructive for employers of future employees, it really depends on how the technology is used. Much of this is merely a broadening of what already happens and there is no evidence, as far as I am aware, that patient confidentiality, for example, has been jeopardised through such avenues, even though the potential is there for it to occur.

One other aspect of this electronic revolution is that we are all now potential journalists. Gone are the days when the only way to get published was to go through a publisher who could and would judge whether or not one's contribution was 'worth' disseminating to a wider audience. Through tweets, blogs, online forums and websites we can tell everyone who will read or listen not only what we think but what we have done, backed up by appropriate (or inappropriate) images. The disadvantage here is that we are equally all potentially swamped by information. No longer do we have to wait for the six-o-clock television news, we can access it at any time as well as learn what an old school friend had for lunch or how a work colleague has chosen autumn-beige paint as their new bedroom décor of choice.

What this means now, and will increasingly mean into the future is that we will rely more and more on somebody to sieve, distil and analyse this plethora of information and information-sources for us. Far from needing less editorial guidance we will all need more. Most importantly it is also likely that we will turn to each of our own 'trusted' sources of information whether for general news content, professional updates, research findings or specialist interests in and out of the workplace. In practice, your job is to ensure that your patients continue their trust in you and your professionalism. Our job at the $B D J$ too is to ensure that we keep your trust, constantly build on it and continue to earn it as we publish what we deem to be relevant and important you.

1. Changes to Dental Provision in the UK and the Implications for the GDC: A Policy Horizon Scanning Report. GDC, London, 2013. Online report available at http:// www.gdc-uk.org/newsand publications/pressreleases/pages/gdc-releases-resultsof-horizon-scanning-exercise.aspx (accessed July 2013). 